\title{
NAIL CHANGES IN CASE OF ENTEROVIRAL INFECTIONS IN WESTERN UKRAINE: A REPORT OF 34 CASES
}

\author{
O. R. Boyarchuk', L. A. Volyanska', O. M. Dyvonyak² \\ ${ }^{1}$ I. HORBACHEVSKY TERNOPIL STATE MEDICAL UNIVERSITY, TERNOPIL, UKRAINE \\ ${ }^{2}$ MUNICIPAL CHILDREN HOSPITAL, TERNOPIL, UKRAINE
}

\begin{abstract}
Background. Enteroviral infections are common infections, mostly affect children. Nail changes of enteroviral infection including transverse ridging (Beau's lines) and nail shedding (onychomadesis) were described in many countries worldwide.

Objective. The aim of the research was to investigate the clinical features of the infection that was followed by nail changes during its outbreak in summer-autumn 2016 in Ternopil region, Ukraine.

Methods. A case report of 34 children with nail changes that were observed in October 2016 in Ternopil region, Ukraine is presented. All patients were from one kindergarten. Nail trauma, periungual dermatitis, significant medication intake history, systemic diseases were excluded. The survey and clinical examination of cases was performed. Faecal samples were obtained from 13 children with onychomadesis.

Results. The median age of the exemined children was 3.97 \pm 0.78 years. Interval between onsets of enteroviral infection to nail changes varied from 4 to 12 weeks. Clinical signs that preceded nail changes are fever (64.7\%), herpangina (32.6\%), pharyngitis (17.6\%), gastrointestinal symptoms (44.1\%), cutaneous lesions (82.4\%) as maculopapular, vesicular rash (44.2\%) or/and skin desquamation (41.2\%). These clinical data indicate preceded enterovirus infection. In 21 (61.8\%) patients hand-foot-mouth disease was suggested.

Nail changes were presented by Beau's lines and onychomadesis (nail shedding). The number of affected nails varied from 1 to 16 , the median number was $4.88 \pm 4.09$.

Conclusions. Our study proved association between the outbreak of onychomadesis (nail shedding) and enteroviral infection, mainly hand-foot-mouth disease, during summer-autumn 2016 in Western Ukraine (Ternopil region). Enteroviral infection was followed by onychomadesis in 4-12 weeks. Clinical features of enteroviral infection were very variable, with prevalence of cutaneous lesions.

More studies are necessary to determine the serotype of the virus that causes onychomadesis.
\end{abstract}

KEY WORDS: enteroviral infections, hand-foot-mouth disease, onychomadesis, children, Ukraine.

\section{Introduction}

Enteroviral infections are commonly encountered infections, caused by group of RNA viruses, especially affect infants and children. Enteroviruses cause more than half of all infectious diseases in children, are accompanied by fever [1-2]. Clinical features of enterovirus infection are very variable; from mild benign fever to life-threatening encephalitis, myocarditis, or sepsis [1].

The enteroviral group includes coxsackievirus, echovirus, and poliovirus. Enteroviral infections may be caused by 23 coxsackievirus A, 6 coxsackievirus B, 28 echovirus, and 5 unclassified enteroviruses.

Corresponding author: Oksana Boyarchuk, Department of Childrens Diseases and Pediatric Surgery, I. Horbachevsky Ternopil State Medical University, 2 Acad. Sakharova Street, Ternopil, Ukraine, 46023

Phone number: +380352269061

E-mail: boyarchuk@tdmu.edu.ua
Hand-foot-mouth disease (HFMD) is one of the forms of enteroviral infections. HFMD is characterized by sores in mouth (vesicular, erosive stomatitis) or on mouth and on hands, feet and sometimes buttocks and legs (maculopapular, vesicular lesions). The most common cause of HFMD is Coxsackievirus A6, A10, A16 and enterovirus $71[2,3]$. First cases of nail changes after HFMD were reported in 2000 in 5 children in Chicago, USA [4]. In Europe first four cases of nail changes following HFMD were described in 2001 [5].

Nail changes of enteroviral infection are described as nail matrix arrest, including transverse ridging (Beau's lines) and nail shedding (onychomadesis) [4, 6]. Short-term slowing down of nail formation leads to Beau's lines, while long-term stop of nail growth causes onychomadesis [7]. 
The aim of the research was to investigate the clinical features of the infection that was associated with nail changes during an outbreak in summer-autumn 2016 in Ternopil region, Ukraine.

\section{Material and Methods}

We present a case report of 34 children with nail changes that were observed in October 2016 in Ternopil region, Ukraine. All patients were from one kindergarten.

Nail trauma, periungual dermatitis, significant medication intake history, systemic diseases were excluded.

The study of cases was performed. It included a questionnaire containing the following parameters: age, gender, personal and family history of the children. A questionnaire was completed by parents.

The patients were clinically examined, and their paediatric and dermatological records were studied to confirm precedent enteroviral infection. Direct microscopic examination and cultures for fungi were performed in the first 3 cases.
Faecal samples were obtained from 16 children with onychomadesis for enterovirus testing.

Parents of all patients provided written informed consent before any study-related procedure. The study conformed to the principles outlined in the declaration of Helsinki.

The results have been analysed using standard procedures with Statistica StatSoft 6.0 software package. Values are expressed as mean \pm standard deviation (SD) for continuous variables and $\mathrm{n}$ (percentages) for categorical variables.

\section{Results}

The median age of the exemined children was 3.97 \pm 0.78 years (range, $2-5$ years). 19 (55.9\%) were male.

All patients were presented with nail changes.

Due to the history of present illnesses it was revealed that interval between onsets of enteroviral infection to nail changes varied from 4 to 12 weeks. Clinical features of enteroviral infection were very variable (Table 1).

Table 1. Clinical features of patients with nail changes after enteroviral infection

\begin{tabular}{|l|c|c|}
\hline Clinical features & $\mathrm{n}$ & $\%$ \\
\hline Fever & 22 & 64.7 \\
\hline Respiratory symptoms & 16 & 47.1 \\
\hline herpangina & 11 & 32.6 \\
\hline pharyngitis & 6 & 17.6 \\
\hline Gastrointestinal symptoms & 15 & 44.1 \\
\hline Cutaneous lesions & 28 & 82.4 \\
\hline maculopapular, vesicular rash & 15 & 44.1 \\
\hline skin desquamation & 14 & 41.2 \\
\hline Conjunctivitis & 2 & 5.9 \\
\hline
\end{tabular}

The average duration of fever was $1.87 \pm 0.92$ days. Maximum temperature varied from 37.6 to $40.0^{\circ} \mathrm{C}$. Gastrointestinal symptoms were presented by nausea, vomiting, diarrhea without blood and mucus. In 7 (20.6\%) cases maculopapular, vesicular rash was on hands, feet and around mouth. Skin rash was followed by skin desquamation in $3(8.8 \%)$ patients in $2-6$ weeks. In other cases skin desquamation occurred in children without history of skin rash. Skin desquamation was both on the palms and soles in $6(17.6 \%)$ cases, only on palms in $3(8.8 \%)$ and only on soles of feet in $5(14.7 \%)$ cases.

The first manifestation of the disease occurred in the middle of summer (July $8 / 23.5 \%$ cases), in August (10/29.4\% cases) and in autumn (September - 13/38.2\% cases). In 3 cases parents did not indicate previous problems or any symptoms of enterovirus infection, so we can suggest asymptomatic duration of the infection.

Faecal samples from onychomadesis patients were positive for enterovirus in one case.

Nail changes were presented by Beau's lines and onychomadesis (nail shedding) (Figure 1-4).

The number of the affected nails varied from 1 to 16 . The mean number of the affected nails was $4.88 \pm 4.09$. Fingernails were involved more often than toenails $(3.79 \pm 2.61$, range 1 to $10 ; 3.31 \pm 2.20$, range 1 to 9 , respectively). In two children we observed changes of toenails colour (Figure 5). 


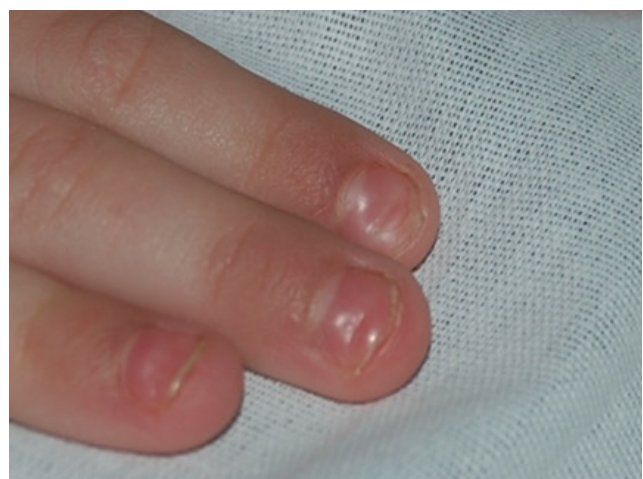

Fig. 1. Beau's lines on the right fingernails after enteroviral infection.

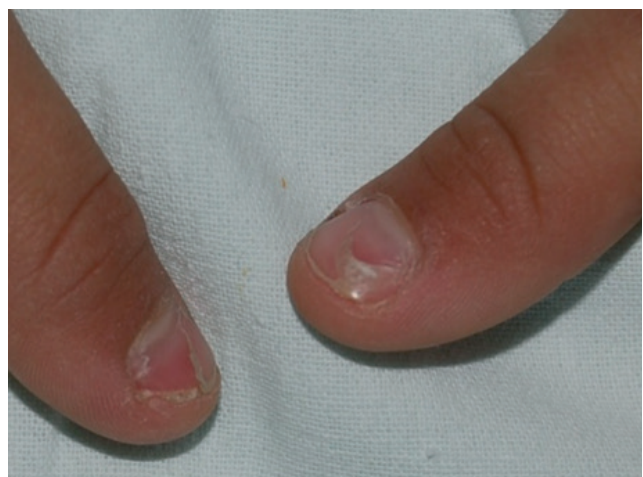

Fig. 3. Onychomadesis on both great fingernails after enteroviral infection.

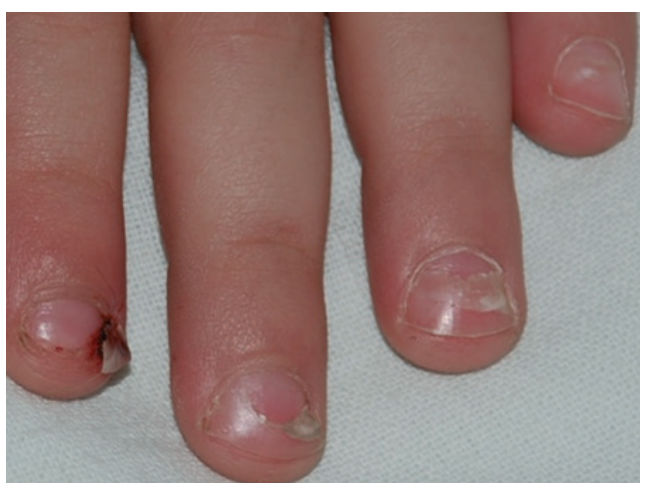

Fig. 2. Different stages of fingernail shedding (onychomadesis) in a 4-year-old child after enteroviral infection.

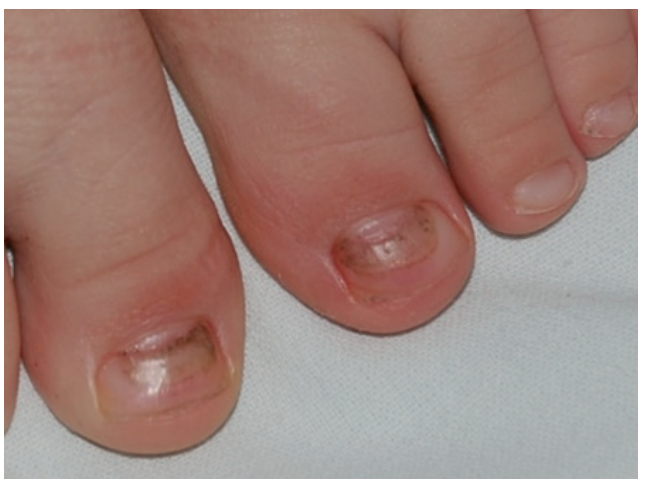

Fig. 4. Beau's lines and onychomadesis on both great toenails after enteroviral infection.

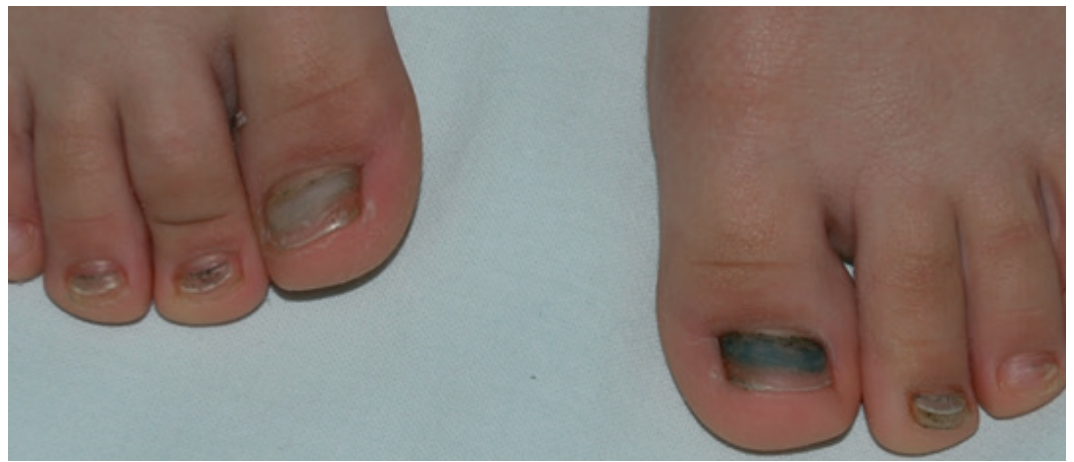

Fig. 5. The deformation of toenail bed, toenail plate thickening and change of its colour.

\section{Discussion}

Since 2000 a lot of enteroviral infection outbreaks associated with nail matrix arrest have been reported throughout the world [812]. Hand-foot-mouth disease was mostly followed by nail changes. However, in Ukraine such cases have been not yet described.

Formerly nail changes were associated with nail trauma, periungual dermatitis, significant medication intake history, autoimmune disorders, etc. Now onychomadesis are described as late complication of enteroviral infection $[6,8]$.

Onychomadesis are caused by a temporary arrest in nail plate formation $[2,8]$, but the enteroviruses influence on this process remains unclear today.

Frequently onychomadesis was associated with coxsackievirus (C) A6 serotype of enterovirus $[10,11]$. However identification of other enteroviral strains (CA10, CA16 and enterovirus 71) was reported too $[9,10,12]$. Enterovirus serotypes CA10 and coxsackievirus B1 were mainly detected as a monoinfection or coinfection in Valencia, Spain, where an onychomadesis outbreak occurred [12].

Osterback R. et al. from Finland [9] detected CVA6 also in a fragment of shed nail. They suggest that virus replication damages nail matrix and results in temporary nail dystrophy. 
The study from Taiwan proves that in 51\% CA6 patients desquamation of palms and soles occurred after the infection episode and in 37\% CA6 patients onychomadesis developed, which only occurred in 7 (5\%) of 145 cases with nonCA6 enterovirus infection [11]. The authors confirmed association of CA6 infection with developing nail abnormalities $(p<0.001)$.

Unfortunately, we were unable to determine the serotype of the virus in our cases. Enterivirus was identified only in one case (6.3\%), probably because of a long period from the first symptoms of the disease. Study in Spain [12] reported about $59 \%$ positive samples collected from 29 onychomadesis case-patients ( 23 with HFMD) and 9 exposed persons (1 with HFMD).

In our study typical preceding clinical signs indicated enteroviral infection. In the most cases $(21 / 61.8 \%)$ cutaneous lesions (maculopapular, vesicular rash and skin desquamation) were located on hands, feet and around the mouth, which indicated HFMD.

Enteroviral diseases in countries with temperate climate are characterized by summerautumn seasonality. Unlike, in tropical countries, where the virus is circulating throughout the

\section{References}

1. de Crom SCM. Rossen, JWA, van Furth AM, Obihara CC. Enterovirus and parechovirus infection in children: a brief overview. Eur J Pediatr 2016; 175: 1023-1029.

2. Shin JY, Cho BK, Park HJ. A Clinical study of nail changes occurring secondary to hand-foot-mouth disease: onychomadesis and Beau's lines. Ann Dermatol 2014; Apr; 26(2): 280-283.

3. Stock I. Hand, foot and mouth disease - more than a harmless "childhood disease". Med Monatsschr Pharm 2014; Jan; 37(1): 4-10; quiz 11-2.

4. Clementz GC, Mancini AJ. Nail matrix arrest following hand-foot-mouth disease: a report of five children. Pediatr Dermatol 2000;17: 7-11.

5. Bernier V, Labrèze C, Bury F, Taïeb A. Nail matrix arrest in the course of hand, foot and mouth disease. Eur J Pediatr 2001; 160: 649-651.

6. Apalla Z, Sotiriou E, Pikou O, Lefaki I, Lallas A, Lazaridou $E$, Ioannides $D$. Onychomadesis after hand-foot-and-mouth disease outbreak in northern Greece: case series and brief review of the literature. Int J Dermatol 2015; 54: 1039-1044.

7. Haneke E. Onychomadesis and hand, foot and mouth disease - is there a connection? Euro Surveill 2010; 15: pil: 19664. year seasonal outbreaks are not typical. The first manifestation of the disease in our cases began in the middle of summer (July) and lasted till autumn (September). An outbreak of HFMD with onychomadesis was reported in Finland in 2008 starting in August and continuing at least until the end of the year [10]. In Valencia, Spain HFMD, followed by onychomadesis occurred during summer and autumn 2008 [12]. But in northern Greece, in the region of Thessaloniki an onychomadesis outbreak related to the outbreak of HFMD occurred during autumnwinter 2012-2013 [6].

\section{Conclusions}

Our study proved association between onychomadesis (nail shedding) outbreak and outbreak of enteroviral infection, mainly handfoot-mouth disease, during summer-autumn 2016 in Western Ukraine (Ternopil region). Enteroviral infection was followed by onychomadesis in 4-12 weeks. Clinical features of enteroviral infection were very variable, with prevalence of cutaneous lesions.

More studies are necessary to determine the serotype of the virus causing onychomadesis.

8. Bettoli V, Zauli S, Toni G, Virgili A. Onychomadesis following hand, foot, and mouth disease: a case report from Italy and review of the literature. Int J Dermatol 2013; 52: 728-730.

9. Davia JL, Bel PH, Ninet VZ, Bracho MA, González-Candelas F, Salazar A, et al. Onychomadesis outbreak in Valencia, Spain associated with hand, foot, and mouth disease caused by enteroviruses. Pediatr Dermatol 2011; 28: 1-5.

10. Osterback R, Vuorinen $T$, Linna M, Susi $P$, Hyypiä T, Waris M. Coxsackievirus A6 and hand, foot, and mouth disease, Finland. Emerg Infect Dis 2009; 15: $1485-1488$.

11. Wei SH, Huang YP, Liu MC, Tsou TP, Lin HC, Lin TL, et al. An outbreak of coxsackievirus A6 hand, foot, and mouth disease associated with onychomadesis in Taiwan, 2010. BMC Infect Dis 2011; 11: 346.

12. Bracho MA, González-Candelas F, Valero A, Córdoba J, Salazar A. Enterovirus co-infections and onychomadesis after hand, foot, and mouth disease, Spain, 2008. Emerg Infect Dis 2011; 17: 2223-2231

Received: 2016-12-03 